\title{
REVIEW
}

\section{The arterial load in pulmonary hypertension}

\author{
N. Saouti*, N. Westerhof*,\#, P.E. Postmus* and A. Vonk-Noordegraaf*
}

\begin{abstract}
The anatomical differences between the pulmonary and systemic arterial system are the main cause of the difference in distribution of compliance. In the pulmonary arterial system compliance is distributed over the entire arterial system, and stands at the basis of the constancy of the RC-time. This distribution depends on the number of peripheral vessels, which is $\sim 8-10$ times more in the pulmonary system than the systemic tree. In the systemic arterial tree the compliance is mainly located in the aorta ( $80 \%$ of total compliance in thoracic-abdominal aorta).

The constant RC-time in the pulmonary bed results in proportionality of systolic and diastolic pressure with mean pressure and, in turn, in the constant ratio of oscillatory and mean power.
\end{abstract}

KEYWORDS: Compliance, pulmonary hypertension, resistance, systemic circulation, Windkessel

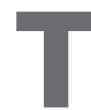

he common feature of pulmonary and the systemic circulation is that both transport an equal amount of blood. However, a major difference is that the pulmonary circulation works at much lower pressures than the systemic circulation. Pulmonary pressure is lower as resistance is lower and the pulmonary vasculature is more compliant. In pulmonary hypertension, the right ventricular load increases due to an increase in pulmonary vascular resistance and decrease in pulmonary vascular compliance, ultimately leading to right ventricular failure. In recent years it has become clear that in pulmonary hypertension not only the contribution of resistance is of importance but that the decrease in arterial compliance plays an equally important role. In addition, in pulmonary hypertension the changes in resistance and compliance are fundamentally and quantitatively different from those in systemic hypertension. Therefore, changes in the pulmonary arterial tree and in pressure are considerably larger than in the systemic arterial tree.

This review describes the most important components of the arterial load on the right ventricle (RV) in terms of resistance and arterial compliance, and the consequences of load changes for right ventricular work and function. We will conclude with a short comparison of the pulmonary and systemic circulation in health and hypertension. While the hydraulic load describes the load that the ventricular pump experiences, the muscles generate and feel wall stress, which is considered the muscular afterload. In general higher impedance relates to higher wall stress.

\section{COMPONENTS OF ARTERIAL LOAD AND HOW THEY ARE MEASURED}

The ventricle ejects blood against the arterial hydraulic load. This load can be described completely by the so-called pulmonary arterial input impedance that accounts for the relationship between pulsatile pressure and flow [1, 2]. However, this description is not only difficult to derive but also complex to interpret.

Therefore, several simplified descriptions of the arterial circulation have been proposed [3-8]. One such a description is the Windkessel model which has impedance close to that of the measured one, and consists of physiologically easily interpretable parameters. This model describes the haemodynamics of the systemic and pulmonary arterial circulation in terms of resistance and compliance (fig. 1) [10]. The resistance of the model is the pulmonary vascular resistance (PVR); which is commonly calculated as the ratio of mean pulmonary artery pressure $\left(\bar{P}_{\text {pa }}\right)$ minus mean pulmonary capillary wedge pressure and cardiac output (CO). Resistance is mainly located in the small arteries and arterioles, since resistance strongly depends on vessel diameter. Poiseuille's law states that resistance is inversely proportional to $\mathrm{D}^{4}$. The compliance $(\mathrm{C})$ of the model is the storage capacity of all arteries and arterioles taken together. If we assume for a moment that the periphery is closed, the increase in pressure $(\Delta \mathrm{P})$ resulting from a single stroke volume (SV) relates to compliance as: $\mathrm{C}=\mathrm{SV} / \Delta \mathrm{P}$. Calculation of compliance is, in practice, more difficult because there is blood leaving the arterial system through the periphery (microcirculation)
AFFILIATIONS

Depts of *Pulmonary Diseases, and \#Physiology, Institute for Cardiovascular Research, VU University Medical Center, Amsterdam, The Netherlands

CORRESPONDENCE

A. Vonk-Noordegraaf Dept of Pulmonary Diseases VU University Medical Center De Boelelaan 1117 1081 HV Amsterdam The Netherlands

E-mail: a.vonk@vumc.nl

Received:

Feb 282010

Accepted after revision:

April 042010

\section{PROVENANCE}

Publication of this peer-reviewed article was supported by Pfizer, Ltd (principal sponsor, European Respiratory Review issue 117). 
while cardiac ejection takes place. However, methods exist to derive compliance in vivo [11-13]. An overview of the methods has been given by WESTERHOF et al. [9]. Herein, we have chosen to use the pulse pressure method, since this method was shown to obtain reliable data $[11,14]$. The model consisting of resistance and compliance is called the 2-element Windkessel and was introduced by FRANK [10].

With the derivation of the input impedance, it became apparent that the Windkessel proposed by FRANK [10] is not complete. During early ejection the blood has to be accelerated, implying that blood mass plays a role and that the blood is ejected in a compliant pulmonary artery. The ratio of mass and compliance is characteristic impedance $\left(Z_{c}\right)$ of the proximal pulmonary artery (or proximal aorta) [8]. The $Z_{c}$ can be calculated from the slopes of pulmonary artery pressure and pulmonary artery flow in early ejection $[2,9]$. It can also be calculated from the input impedance at high frequencies [2,9]. Characteristic impedance is related to the wave speed (c) as:

$$
\mathrm{Z}_{\mathrm{c}}=\mathrm{c} \times \rho / \mathrm{A}
$$

Where $\rho$ and A equal blood density and cross-sectional area of the pulmonary artery, respectively [8]. Adding $Z_{c}$ to the Windkessel model results in the 3-element Windkessel. Thus, this model consists of resistance, compliance and characteristic impedance, accurately describes the input impedance, and all three parameters have a physiological meaning and can be determined in vivo.

Compliance is related to arterial wall elasticity and vessel size (i.e. radius and wall thickness); elastic arteries have a large compliance and stiff arteries a small compliance. The compliance of the arterial tree allows the arteries to expand passively during systole and to recoil during diastole. This has two important effects. 1) The compliant arteries are able to store the ejected blood volume in systole and release this volume during diastole resulting in constant peripheral blood flow throughout the entire cardiac cycle. 2) The compliant arteries damp/cushion the pressure so that pressure variations

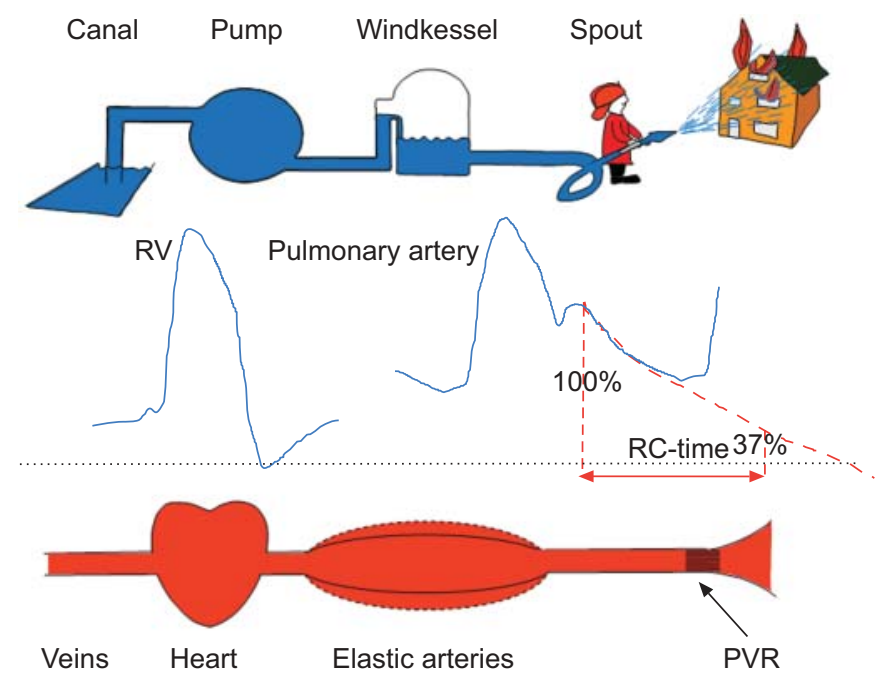

FIGURE 1. Comparison of the circulation with a fire engine. The Windkessel is an air reservoir. RV: right ventricle; PVR: pulmonary vascular resistance. Adapted from [9] with permission from the publisher. in the pulmonary artery are smaller than in the ventricle. In other words, in diastole the pressure in the pulmonary artery decreases much less than in the right ventricle.

The decrease of pressure in diastole depends on PVR and compliance. A large PVR means small run-off through the periphery and a small pressure decrease. A large compliance implies a large storage volume which also results in a small pressure decrease in diastole. This combined effect can be formulated by the product of PVR and compliance, the unit of this product is time $(\tau=\mathrm{R} \times \mathrm{C}, \mathrm{s})$ and, therefore, called the arterial time-constant, since PVR and compliance depend on the arterial tree and not on the heart. In reality this means that we can characterise the decay of pressure in diastole by a socalled exponential decrease with RC-time $\tau$ (figs 1 and 2).

\section{THE INVERSE RELATIONSHIP BETWEEN RESISTANCE AND COMPLIANCE: THEIR PRODUCT IS CONSTANT}

In pulmonary arterial hypertension $(\mathrm{PAH})$ the elevated $\bar{P}_{\text {pa }}$ results from progressive vascular remodelling, vasoconstriction and thrombosis of small pulmonary arteries [15-17], and therefore from the resistance increase. Clinicians usually define right ventricular (after)load in terms of PVR and this measure is often used as a primary or secondary end-point in clinical studies [18-21]. However, this measure only reflects the nonpulsatile (steady) component of blood flow, and neglects the important contribution of compliance. Compliance namely takes into account the pulsatile components of the arterial load and, therefore, compliance (or stiffness; the reciprocal of compliance) is an important factor contributing to systolic and diastolic pressure. In turn, systolic pressure determines systolic wall stress the true afterload on the cardiac muscle. The pulmonary arterial pulse pressure (PP; systolic minus diastolic pressure) is approximately equal to mean pressure (ratio of PP and mean pressure $\sim 1$ ) and is much larger than the ratio of systemic arterial PP and mean pressure ( 0.40) (fig. 3). This larger ratio emphasises the contribution of arterial compliance to PP (and systolic pressure) in the pulmonary arterial system. Systolic pressure and PP are prognostic factors in systemic hypertension $[22,23]$, but this is not as clear in PAH. On the one hand pulmonary compliance was shown to be a prognostic factor for mortality [24], but on the other hand PP did not independently predict mortality [25].

To understand the haemodynamics of the pulmonary circulation in PAH, studies have been performed where PVR and compliance have been measured in healthy subjects and patients [26, 27]. The findings showed that resistance and compliance in the pulmonary circulation are inversely related by a hyperbola (fig. 4) [26-28]. In other words, the product, i.e. the RC-time, in the pulmonary circulation remains the same in healthy individuals and in patients with $\mathrm{PAH}$ and chronic thromboembolic pulmonary hypertension, and even after treatment. The ranges of PVR and compliance are given in table 1 . The study by LANKHAAR et al. [26] also showed that PVR and compliance in combination describe the RV afterload better than either PVR or compliance separately.

Figure 4 shows that in the early stage of PAH a small increase in PVR will be accompanied by a relatively large drop in compliance. However, in the late stage when the vascular disease progresses, the increase in PVR will continue but the 


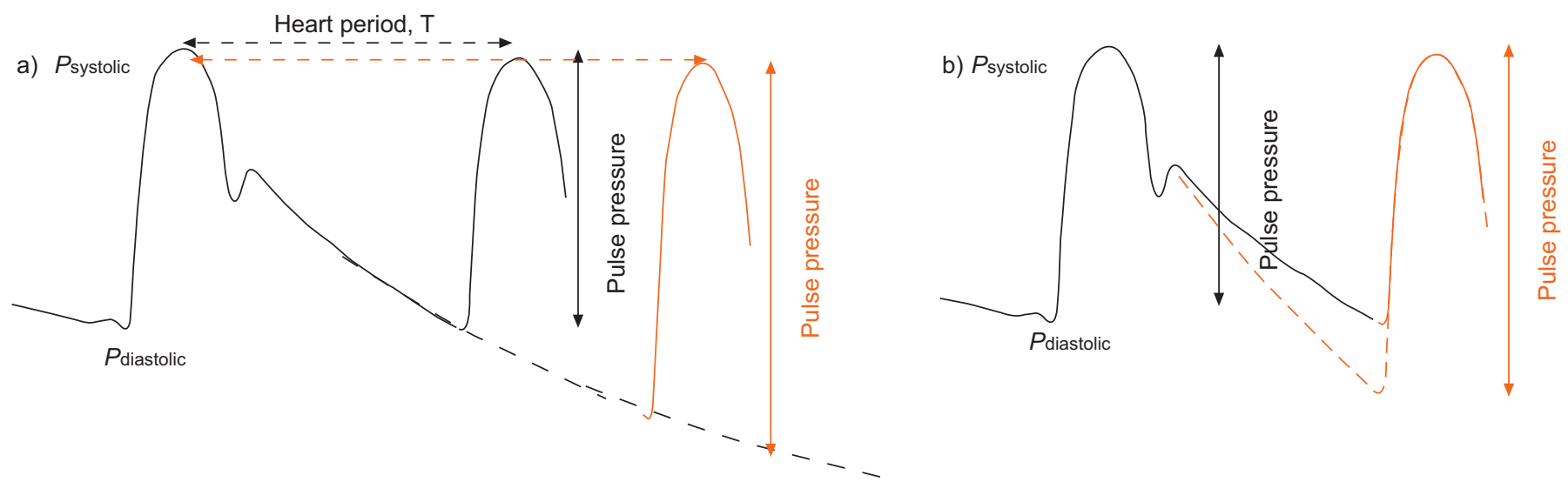

FIGURE 2. Schematic presentation of the effect of a decrease in a) heart rate and b) a shorter RC-time on pulse pressure (PP). A longer heart period equals a lower heart rate and a larger PP. A shorter RC-time, compliance and/or a pulmonary resistance decrease results in a larger PP. Psystolic: systolic pressure; Pdiastolic: diastolic pressure.

drop in compliance will be limited as the vascular wall stiffness will reach a maximum.

We conclude that the early changes in the pulmonary vascular bed are characterised by the fact that a small change in PVR leads to a considerable change in compliance and can, therefore, be better detected by a change in compliance than a change in PVR.

It has been shown that at a given flow, arterial resistance and compliance are the main arterial parameters that determine PP [29]. The effect of RC-time and heart rate (HR, equal to $1 /$ heart period, T) on PP are shown in figure 2. A lower HR (thus longer heart period) increases PP and a shorter RC-time also increases PP. Since, in approximation $\mathrm{C}=\mathrm{SV} / \mathrm{PP}$ and $\mathrm{R}=$ Pmean $/ \mathrm{CO}$ or Pmean $/ \mathrm{SV} \times \mathrm{HR}$, the $\mathrm{T} / \mathrm{RC}$ is approximately equal to PP/Pmean. When HR is not much different and with constant $\mathrm{RC}$, the ratio of $\mathrm{PP}$ over mean pressure is $\sim 0.4$ in health and hypertension.

\section{WHY THE PRODUCT OF RESISTANCE AND COMPLIANCE IS CONSTANT}

Recently, PVR and compliance were determined in single lungs and in lungs with emboli. It could be shown that the constant RC-time is an intrinsic property of a single lung and remains constant when emboli are present. This implies that the inverse relationship between PVR and compliance holds true for a single lung and for parts of lungs. From this it follows that if one lung is removed PVR will be doubled while compliance will be reduced to half, and the product remains the same [30].

There are two reasons to explain the consistency of the product of resistance and compliance. The first is based on basic arterial properties and, thus, occurs in both the pulmonary and systemic arterial circulation. An increase in vascular resistance will lead to an increased intravascular pressure and, due to the nonlinear elasticity of arteries [31,32], elevated pressure will result in stiffer arteries and thus reduced compliance [33-38]. The second mechanism is based on the anatomy of the pulmonary arterial system. It has been shown that together the common pulmonary artery and proximal left and right arteries contribute only $15-20 \%$ to total arterial compliance, suggesting that arterial compliance is distributed over the entire pulmonary arterial bed [30]. If we assume the following estimation it becomes clear how important peripheral arteries are in their contribution to compliance: total number of
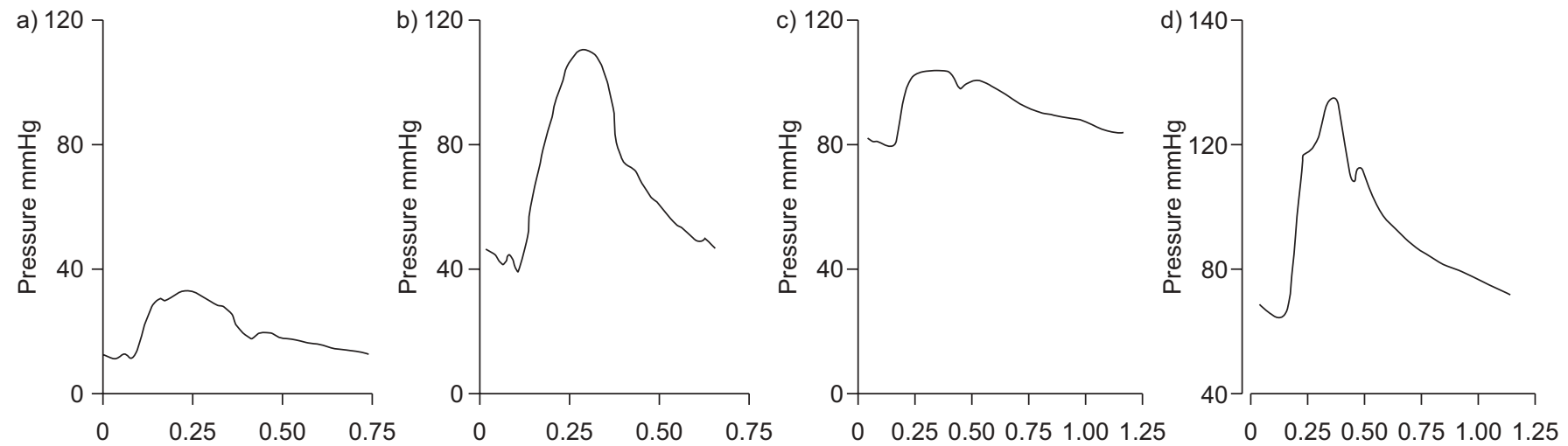

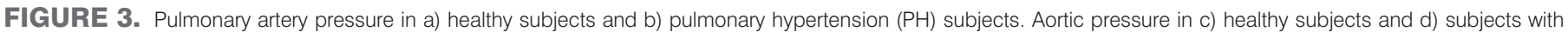

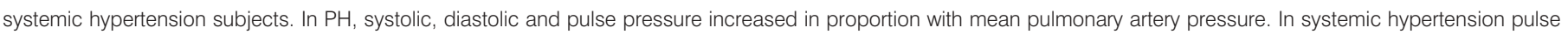
pressure increases much more than mean aortic pressure and diastolic pressure may even decrease. 


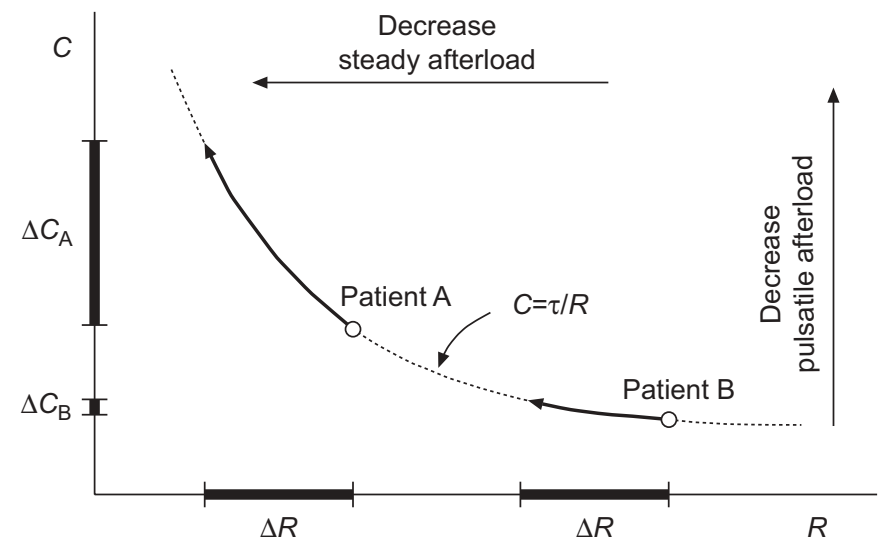

FIGURE 4. Inverse hyperbolic relationship between pulmonary arterial compliance (C) and pulmonary resistance (R). $\Delta$ : change. Reproduced from [27] with permission from the publisher.

arterioles with a length of $2 \mathrm{~mm}$ and diameter of $8 \mu \mathrm{m}$ is $\sim 4 \times 10^{9}[39,40]$. One such arteriole has a compliance of $\sim 0.5 \times 10^{-9} \mathrm{~mL} \cdot \mathrm{mmHg}^{-1}$. Total compliance in periphery is, therefore, $4 \times 10^{9} \times 0.5 \times 10^{-9}=2 \mathrm{~mL} \cdot \mathrm{mmHg}^{-1}$. Since the whole pulmonary arterial system has a compliance of $\sim 4 \mathrm{~mL} \cdot \mathrm{mmHg}^{-1}$ (table 1), a large part of arterial compliance is located in the periphery. This estimate is in line with earlier publications showing that a considerable proportion of the pulmonary arterial compliance is distal to the proximal large arteries [30, 40-46]. Thus, with an embolus (large) part of peripheral arteries is lost meaning that their compliance is lost resulting in a decrease of the total compliance, and by the loss of vessels the resistance is increased.

In contrast to the distribution of compliance in the pulmonary circulation, in the systemic circulation the number of arterioles is $\sim 10$ times smaller, with resistance 10 times larger and compliance 10 times smaller. Thus, in the systemic circulation the resistance is mainly located in the distal small arteries and arterioles, and compliance is mainly located in the aorta $[7,12,47]$. In old age hypertension, primarily the stiffness of the aorta is affected which means that total arterial compliance is decreased but resistance is only slightly affected. This explains the change in the RC-time when systemic arterial load increases as in old age hypertension.

We conclude that in the pulmonary circulation, arterial compliance is distributed over the entire arterial tree. This means that occlusion of a whole lung or lobe or segment not only increases resistance but also decreases compliance.

\section{CONSEQUENCES OF THE CONSTANT PRODUCT OF RESISTANCE AND COMPLIANCE}

\section{Proportional relationship of systolic and diastolic pressure and $\bar{P}_{\text {pa }}$}

We have previously reasoned that with a constant RC-time and $\mathrm{HR}$ the ratio of $\mathrm{PP}$ and mean pressure remains the same. Since mean pressure also depends on both systolic and diastolic pressure, we can derive that a proportional relationship should exist between systolic and diastolic pulmonary artery pressure with mean pressure. These proportional relationships indeed remain over a wide range of pulmonary artery pressures in healthy individuals and PAH (fig. 5) [48, 49]. Thus, we propose that these proportional relationships are the reflection of the hyperbolic relationship between PVR and arterial compliance.

The linear relationship between $\bar{P}_{\mathrm{pa}}$ and both systolic and diastolic pulmonary artery pressure implies that $\bar{P}_{\mathrm{pa}}$ is a measure for systolic pulmonary artery pressure and can be calculated by: $\bar{P}_{\mathrm{pa}}=0.61 \times$ systolic pulmonary artery pressure $+2 \mathrm{mmHg}$ [50]. The advantage of measuring $\bar{P}_{\mathrm{pa}}$ is that this pressure is less affected by catheter artefacts than systolic pressure. The proportionality also implies that an estimated systolic pulmonary artery pressure by cardiac echocardiography can provide a good measure of $\bar{P}$ pa. However, to derive more data on pulmonary haemodynamics, like detailed pressure wave shapes, right heart catheterisation remains essential for diagnosing PAH.

The proportional relationship between systolic and diastolic pressure with mean pressure (fig. 5) implies proportionality of PP with mean pressure as well. Therefore, we hypothesise that mean, systolic and diastolic pressure and PP all have a similar prognostic value.

\section{The ratio of oscillatory power and total power is constant}

The energy used by the heart to propel blood to the arterial circulation is called the external hydraulic power and consists of two components. Mean hydraulic power is the energy used to produce net mean flow and is the product of $\bar{P}_{\mathrm{pa}}$ and mean flow. The energy used in the production of the pulsatile components of flow and pressure is the oscillatory (or pulsatile) hydraulic power [51, 52]. Oscillatory power can be considered as not useful because it is not related to net transport of blood. Since oscillatory flow and pressure pulsations in the pulmonary artery are considerable, and PP is about equal to mean pressure, the oscillatory power is also considerable. It has been found that oscillatory power is $\sim 23 \%$ of total power (and mean power plus oscillatory power being total power is $23 /(100-23)=23 / 77$ or $\sim 30 \%$ of mean power), and that this fraction is remains the same in healthy subjects

TABLE 1 Windkessel parameters and time constant in the pulmonary and systemic arterial system

\begin{tabular}{lcccc} 
& $\begin{array}{c}\text { Pulmonary tree } \\
\text { normal }\end{array}$ & $\begin{array}{c}\text { Pulmonary tree } \\
\text { hypertension }\end{array}$ & $\begin{array}{c}\text { Systemic tree } \\
\text { normal }\end{array}$ & $\begin{array}{c}\text { Systemic tree old age } \\
\text { hypertension }\end{array}$ \\
\hline Compliance $\mathbf{m L} \cdot \mathbf{m m H g} \mathbf{m}^{-1}$ & 3.8 & 0.2 & 2.5 & 0.8 \\
Resistance $\mathbf{m m H g} \cdot \mathbf{s} \cdot \mathrm{mL}^{-1}$ & 0.11 & 2.0 & 1.0 & 1.2 \\
RC-time $\tau \mathbf{s}$ & 0.4 & 0.4 & 2.5 & 1.0 \\
\hline
\end{tabular}




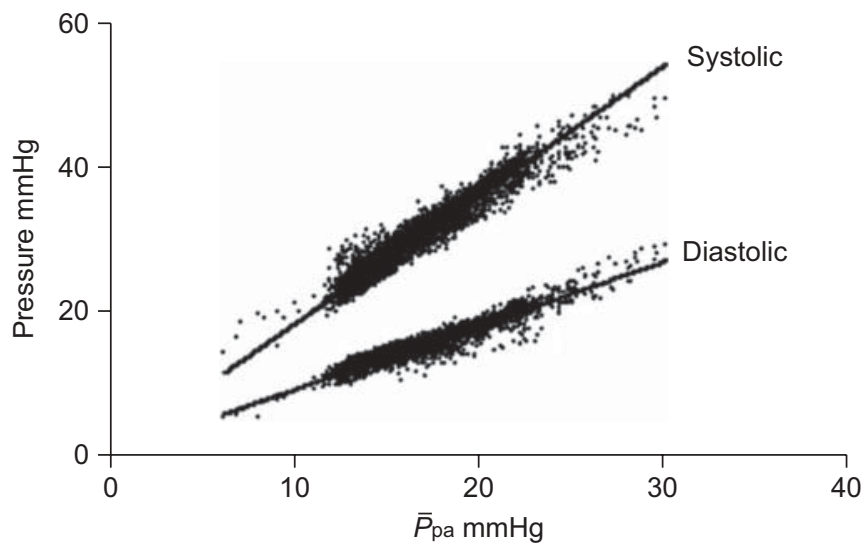

FIGURE 5. Proportional relationship between systolic and diastolic pulmonary artery pressures with mean pulmonary artery pressure $\left(\bar{P}_{\text {pa) }}\right.$. Systolic: $y=1.49 \mathrm{x}$, $R^{2}=0.93$; diastolic: $y=0.74 x, R^{2}=0.91$. Reproduced from [48] with permission from the publisher.

and in subjects with PAH [53]. This constant fraction is the result of the proportionality of pressures, (mean over systolic pressure) and, therefore, also follows on from the constancy of RC. Thus, vasodilation by decreasing pressure and, as such, power output, does reduce the oscillatory component with the same proportion as the mean power.

We conclude that the constant RC-time of the arterial system results in proportionality between systolic and diastolic pressure and $\bar{P}_{\mathrm{pa}}$ and, in addition, is the reason why oscillatory power remains a constant fraction of total power in health and disease.

\section{COMPARISON OF PULMONARY AND SYSTEMIC CIRCULATION}

A major difference with the systemic arterial system, where almost all compliance is central, and the pulmonary arterial system is that the latter has a compliance which is more equally distributed over the whole arterial system. Thus, this anatomical difference, in which compliance and resistance are inseparably connected over the pulmonary arterial tree, results in a constant RC product. Vice versa, the anatomical separation of compliance (central) and resistance (peripheral) in the systemic arterial tree results in a non-constant RC product (table 1).

This has the following consequences. 1) Proportionality of pulmonary artery pressures (fig. 5) and no proportional relationship of systemic arterial pressures. 2) $\mathrm{PP}$ in the aorta is $40 \%$ of mean systemic pressure versus PP is $100 \%$ of $\bar{P}_{\text {pa }}$ (fig 3). 3) Ranges in pressures in systemic hypertension are relatively small compared to the extremely large range in pressures in pulmonary hypertension (fig. 6). Even still, the changes in compliance and resistance are much larger in the pulmonary system than in the systemic system. For instance, in (old age) systemic hypertension, resistance increases by only $\sim 20 \%$ whereas compliance can decrease by a factor of three (table 1). In contrast, in pulmonary hypertension resistance can increase by a factor of 18 and compliance can decrease by a factor of 20 (table 1). 4) Oscillatory power fraction (ratio of oscillatory to mean power) of the left ventricle is only $\sim 10-13 \%$ and increases in systemic hypertension [52, 54]. Oscillations play a more important role in the pulmonary vascular bed and,
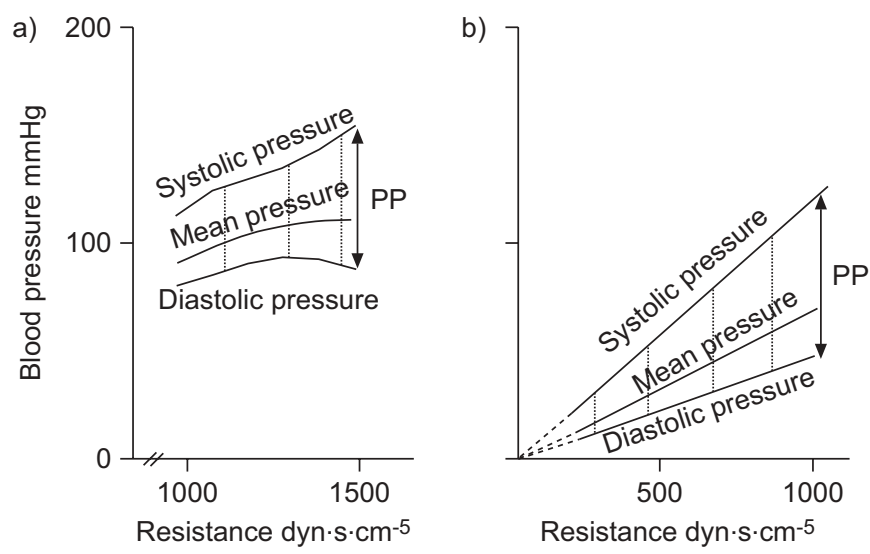

FIGURE 6. a) In systemic circulation when pressure increases (old age hypertension) systolic, diastolic and mean pressure are not linearly related. b) In contrast, pressure increases linearly in pulmonary hypertension. Note also that the range in pressures and resistance are extremely large in pulmonary circulation (b) in comparison to systemic circulation (a). PP: pulse pressure.

therefore, the RV oscillatory power fraction is much larger (23$33 \%)[36,55]$ than in its systemic counterpart. However, in contrast to systemic hypertension oscillatory power fraction remains constant in pulmonary hypertension [53].

\section{CONCLUSIONS}

The anatomical differences between the pulmonary and systemic arterial system are the main cause of the difference in the distribution of compliance. Compliance in the pulmonary arterial system is distributed over the entire arterial system and stands at the basis of the constancy of the RC time. This distribution depends on the number of peripheral vessels, which is $\sim 8-10$ times more in the pulmonary system than in the systemic tree. In the systemic arterial tree the compliance is mainly located in the aorta $(80 \%$ of total compliance in thoracic-abdominal aorta).

The constant RC-time in the pulmonary bed results in proportionality of systolic and diastolic with mean pressure and, in turn, in the constant ratio of oscillatory and mean power.

\section{STATEMENT OF INTEREST}

N. Saouti and A. Vonk-Noordegraaf were supported by the Netherlands Organisation for Scientific Research (the Hague, the Netherlands), Mozaiek grant (project number 017.003.019) and Vidi grant (project number 917.96.306), respectively.

\section{REFERENCES}

1 Milnor WR, ed. Hemodynamics. 2nd Edn. Baltimore, Williams and Wilkins, 1989.

2 Nichols WW, O'Rourke MF, eds. McDonald's Blood Flow in Arteries: Theoretical, Experimental and Clinical Principles. 5th Edn. London, Hodder Arnold, 2005.

3 Burattini R, Knowlen GG, Campbell KB. Two arterial effective reflecting sites may appear as one to the heart. Circ Res 1991; 68: 85-99.

4 O'Rourke MF. Pressure and flow waves in systemic arteries and the anatomical design of the arterial system. J Appl Physiol 1967; 23: 139-149. 
5 O'Rourke MF, Avolio AP. Pulsatile flow and pressure in human systemic arteries. Studies in man and in a multibranched model of the human systemic arterial tree. Circ Res 1980; 46: 363-372.

6 Stergiopulos N, Young DF, Rogge TR. Computer simulation of arterial flow with applications to arterial and aortic stenoses. J Biomech 1992; 25: 1477-1488.

7 Westerhof N, Bosman F, De Vries CJ, et al. Analog studies of the human systemic arterial tree. J Biomech 1969; 2: 121-143.

8 Westerhof N, Elzinga G, Sipkema P. An artificial arterial system for pumping hearts. J Appl Physiol 1971; 31: 776-781.

9 Westerhof N, Stergiopulos N, Noble MIM, eds. Snapshots of Hemodynamics: An Aid for Clinical Research and Graduate Education. 2nd Edn. New York, Springer, 2010.

10 Frank O. Die Grundform des arteriellen Pulses. Zeitschrift für Biologie 1899; 37: 483-526.

11 Segers $\mathrm{P}$, Brimioulle $\mathrm{S}$, Stergiopulos $\mathrm{N}$, et al. Pulmonary arterial compliance in dogs and pigs: the three-element windkessel model revisited. Am J Physiol 1999; 277: H725-H731.

12 Stergiopulos N, Segers $\mathrm{P}$, Westerhof N. Use of pulse pressure method for estimating total arterial compliance in vivo. Am J Physiol 1999; 276: H424-H428.

13 Vulliemoz S, Stergiopulos N, Meuli R. Estimation of local aortic elastic properties with MRI. Magn Reson Med 2002; 47: 649-654.

14 Stergiopulos N, Meister JJ, Westerhof N. Evaluation of methods for estimation of total arterial compliance. Am J Physiol 1995; 268: H1540-H1548.

15 Pietra GG, Capron F, Stewart S, et al. Pathologic assessment of vasculopathies in pulmonary hypertension. J Am Coll Cardiol 2004; 43: Suppl. 12, 25S-32S.

16 Stewart S, Rassl D. Advances in the understanding and classification of pulmonary hypertension. Histopathology 2009; 54: 104-116.

17 Wagenvoort CA. Plexogenic arteriopathy. Thorax 1994; 49: Suppl., S39-S45.

18 Barst RJ, Langleben D, Frost A, et al. Sitaxsentan therapy for pulmonary arterial hypertension. Am J Respir Crit Care Med 2004; 169: 441-447.

19 Channick RN, Simonneau G, Sitbon O, et al. Effects of the dual endothelin-receptor antagonist bosentan in patients with pulmonary hypertension: a randomised placebo-controlled study. Lancet 2001; 358: 1119-1123.

20 Jais X, D'Armini AM, Jansa P, et al. Bosentan for treatment of inoperable chronic thromboembolic pulmonary hypertension: BENEFiT (Bosentan Effects in iNopErable Forms of chronIc Thromboembolic pulmonary hypertension), a randomized, placebo-controlled trial. J Am Coll Cardiol 2008; 52: 2127-2134.

21 Voswinckel R, Enke B, Reichenberger F, et al. Favorable effects of inhaled treprostinil in severe pulmonary hypertension: results from randomized controlled pilot studies. J Am Coll Cardiol 2006; 48: 1672-1681.

22 Benetos A, Safar M, Rudnichi A, et al. Pulse pressure: a predictor of long-term cardiovascular mortality in a French male population. Hypertension 1997; 30: 1410-1415.

23 Mitchell GF, Moye LA, Braunwald E, et al. Sphygmomanometrically determined pulse pressure is a powerful independent predictor of recurrent events after myocardial infarction in patients with impaired left ventricular function. SAVE investigators. Survival and Ventricular Enlargement. Circulation 1997; 96: 4254-4260.

24 Mahapatra S, Nishimura RA, Sorajja P, et al. Relationship of pulmonary arterial capacitance and mortality in idiopathic pulmonary arterial hypertension. J Am Coll Cardiol 2006; 47: 799-803.

25 Blyth KG, Syyed R, Chalmers J, et al. Pulmonary arterial pulse pressure and mortality in pulmonary arterial hypertension. Respir Med 2007; 101: 2495-2501.

26 Lankhaar JW, Westerhof N, Faes TJ, et al. Quantification of right ventricular afterload in patients with and without pulmonary hypertension. Am J Physiol Heart Circ Physiol 2006; 291: H1731-H1737.
27 Lankhaar JW, Westerhof N, Faes TJ, et al. Pulmonary vascular resistance and compliance stay inversely related during treatment of pulmonary hypertension. Eur Heart J 2008; 29: 1688-1695.

28 Reuben SR. Compliance of the human pulmonary arterial system in disease. Circ Res 1971; 29: 40-50.

29 Stergiopulos N, Westerhof N. Determinants of pulse pressure. Hypertension 1998; 32: 556-559.

30 Saouti N, Westerhof N, Helderman F, et al. RC time constant of single lung equals that of both lungs together: a study in chronic thromboembolic pulmonary hypertension. Am J Physiol Heart Circ Physiol 2009; 297: H2154-H2160.

31 Bergel DH. The dynamic elastic properties of the arterial wall J Physiol 1961; 156: 458-469.

32 Dobrin PB. Mechanical properties of arterises. Physiol Rev 1978; 58 : 397-460.

33 Gan CT, Lankhaar JW, Westerhof N, et al. Noninvasively assessed pulmonary artery stiffness predicts mortality in pulmonary arterial hypertension. Chest 2007; 132: 1906-1912.

34 Hopkins WE, Feinberg MS, Barzilai B. Automated determination of pulmonary artery pulsatility during transesophageal echocardiography. Am J Cardiol 1995; 76: 411-414.

35 Jarmakani JM, Graham TP Jr, Benson DW Jr, et al. In vivo pressureradius relationships of the pulmonary artery in children with congenital heart disease. Circulation 1971; 43: 585-592.

36 Milnor WR, Conti CR, Lewis KB, et al. Pulmonary arterial pulse wave velocity and impedance in man. Circ Res 1969; 25: 637-649.

37 Sanz J, Kariisa M, Dellegrottaglie S, et al. Evaluation of pulmonary artery stiffness in pulmonary hypertension with cardiac magnetic resonance. JACC Cardiovasc Imaging 2009; 2: 286-295.

38 Tozzi CA, Christiansen DL, Poiani GJ, et al. Excess collagen in hypertensive pulmonary arteries decreases vascular distensibility. Am J Respir Crit Care Med 1994; 149: 1317-1326.

39 Horsfield K. Morphometry of the small pulmonary arteries in man. Circ Res 1978; 42: 593-597.

40 Wiener F, Morkin E, Skalak R, et al. Wave propagation in the pulmonary circulation. Circ Res 1966; 19: 834-850.

41 Engelberg J, Dubois AB. Mechanics of pulmonary circulation in isolated rabbit lungs. Am J Physiol 1959; 196: 401-414.

42 Krenz GS, Dawson CA. Flow and pressure distributions in vascular networks consisting of distensible vessels. Am J Physiol Heart Circ Physiol 2003; 284: H2192-H2203.

43 Patel DJ, De Freitas FM, Mallos AJ. Mechanical function of the main pulmonary artery. J Appl Physiol 1962; 17: 205-208.

44 Reeves JT, Linehan JH, Stenmark KR. Distensibility of the normal human lung circulation during exercise. Am J Physiol Lung Cell Mol Physiol 2005; 288: L419-L425.

45 Sniderman AD, Fitchett DH. Vasodilators and pulmonary arterial hypertension: the paradox of therapeutic success and clinical failure. Int J Cardiol 1988; 20: 173-181.

46 Dawson CA, Rickaby DA, Linehan JH, et al. Distributions of vascular volume and compliance in the lung. J Appl Physiol 1988; 64: 266-273

47 Sipkema $\mathrm{P}$, Latham RD, Westerhof $\mathrm{N}$, et al. Isolated aorta setup for hemodynamic studies. Ann Biomed Eng 1990; 18: 491-503.

48 Syyed R, Reeves JT, Welsh D, et al. The relationship between the components of pulmonary artery pressure remains constant under all conditions in both health and disease. Chest 2008; 133: 633-639.

49 Chemla D, Castelain V, Humbert $M$, et al. New formula for predicting mean pulmonary artery pressure using systolic pulmonary artery pressure. Chest 2004; 126: 1313-1317.

50 Chemla D, Castelain V, Provencher S, et al. Evaluation of various empirical formulas for estimating mean pulmonary artery pressure by using systolic pulmonary artery pressure in adults. Chest 2009; 135: 760-768.

51 Milnor WR, Bergel DH, Bargainer JD. Hydraulic power associated with pulmonary blood flow and its relation to heart rate. Circ Res 1966; 19: 467-480. 
52 O'Rourke MF. Steady and pulsatile energy losses in the systemic circulation under normal conditions and in simulated arterial disease. Cardiovasc Res 1967; 1: 313-326.

53 Saouti N, Westerhof N, Helderman F, et al. Right ventricular oscillatory power is a constant fraction of total power irrespective of pulmonary artery pressure. Am J Respir Crit Care Med 2010 (in press).
54 Nichols WW, O'Rourke MF, Avolio AP, et al. Ventricular/vascular interaction in patients with mild systemic hypertension and normal peripheral resistance. Circulation 1986; 74: 455-462.

55 Laskey WK, Ferrari VA, Palevsky HI, et al. Ejection characteristics in primary pulmonary hypertension. Am J Cardiol 1993; 71: 1111-1114. 